\title{
Preparation and Some Properties of Polypeptide Elongation Factors from the Pollen of Pinus densiflora Sieb. et Zucc.
}

\author{
Shin-ichiro EJIRI, Masaaki NunOMIYA and Teizo Katsumata \\ Laboratory of Biochemistry, Department of Agricultural Chemistry, \\ Iwate University, Morioka, Iwate, Japan \\ Received February 9, 1976
}

\begin{abstract}
A cell-free protein synthesizing system was obtained for the first time from the pollen of Pinus densiflora. This system consisted of pollen ribosomes and partially purified pollen polypeptide elongation factors. Procedures were described for the complete resolution and partial purification of the two elongation factors $(E F-1$ and $E F-2)$. One of the factors, $E F-1$, catalyzed a GTP-dependent binding of aminoacyl-tRNA to ribosomes. The second factor $\mathrm{EF}-2$ catalyzed the polyphenylalanine synthesis in the presence of EF-1. Complete exchangeability was observed between pollen EF-1 and the silk gland $E F-1$, or between pollen EF-2 and the silk gland EF-2. Pollen EF-1 was heterogeneous in size; i. e. multiple forms. A larger form of EF-1 had a molecular weight of about 160,000 and the smaller one had molecular weight of about 60,000 . The former was converted into the low molecular weight form in the process of germination and purification.
\end{abstract}

Most of the informations about the mechanisms of peptide elongation were elucidated from the studies on bacterial and mammalian systems. ${ }^{1 \sim 5}$ ) Now that the emphasis of the research in this field is shifting towards the studies of the regulation of protein synthesis in higher organisms, the study of plant systems would be useful and important. However, little information is obtained about plant elongation factors. $^{\theta \sim 13)}$

In this communication, the pollen of Pinus densiflora (pine pollen) is used to clarify the mechanisms of protein synthesis and its control during the germination of pollen. As the germination of pine pollen was inhibited by antibiotics which block protein synthesis (cycloheximide, blasticidin S), the process of germination may be coupled tightly with protein synthesis. Although many enzymes are detected in various pollen, ${ }^{14 \sim 25)}$ it is not clear what sorts of them are synthesized before or after the germination and what are their functions in the germination. To answer these interesting questions it is important to know the features of the machinery of the protein synthesis. Some results were obtained as for the conversion of single ribosomes to polysomes during the germination of pollen, ${ }^{26 \sim 30}$ however, there is no information about elongation factors which are most important factors in protein synthesis. Although, attempts had been made to establish cellfree protein synthesizing system of pollen, only partial success had been made with heterologous combinations of pollen ribosomes and rat liver supernatants. ${ }^{29)}$

The present investigation describes the isolation, characterization and species specificity of the pine pollen elongation factors. Changes of activities and characteristics of them during the germination are also described. This is the first report of the cell-free protein synthesizing system of pollen with ribosomes and two elongation factors (EF-1 and EF-2) of pollen.

\section{MATERIALS AND METHODS}

Materials. Pollen of Pinus densifora Sieb. et Zucc. was collected from the anther just before dehiscence and stored at $-20^{\circ} \mathrm{C}$ for about 3 months, and used for the preparation of ribosomes and elongation factors.

Preparation of ribosomes from pollen. Ten grams of ungerminated pollen were washed with water and 
suspended in 10 volumes of buffer $1(0.02 \mathrm{M}$ Tris- $\mathrm{HCl}$ buffer, pH 7.6, $0.4 \mathrm{M}$ sucrose, $45 \mathrm{~mm} \mathrm{KCl}, 4 \mathrm{~mm} \mathrm{MgCl}$. and $6 \mathrm{mM} \mathrm{2-mercaptoethanol)} \mathrm{and} \mathrm{disrupted} \mathrm{with} \mathrm{a}$ French press (Ōtake seisakusho, Co., Ltd.) at 300 $600 \mathrm{~kg} / \mathrm{cm}^{2}$. Cell debris, nuclei, starch and mitochondoria were removed by centrifugation at $8500 \times g$ for $15 \mathrm{~min}$ and the supernatant fraction was centrifuged at $105,000 \mathrm{~g}$ for $90 \mathrm{~min}$. The precipitate was suspended in buffer I which contains $0.5 \mathrm{M} \mathrm{NH}_{4} \mathrm{Cl}$ and washed twice by centrifugation at $105,000 \times g$ for 90 min. The precipitate was resuspended in buffer $I$ and purified by centrifugation at $14,000 \times g$ for $10 \mathrm{~min}$. The supernatant fraction was used as pollen ribosomes. Silk gland ribosomes were prepared as described previously. ${ }^{31)}$

Preparation of crude elongation factors from pollen. The supernatant fluid obtained by centrifugation at $105,000 \% \mathrm{~g}$ as described for the preparation of ribosomes, was adjusted to $\mathrm{pH} 7.5$ with $0.2 \mathrm{~N} \mathrm{KOH}$, and then the crude elongation factors were precipitated with 0.6 saturation of ammonium sulfate.

Hydroxylapatite column chromatography of crude elongation factors. The fraction precipitated with ammonium sulfate was dissolved in buffer II $0.05 \mathrm{M}$ potassium phosphate buffer, $\mathrm{pH} 7.6,2 \mathrm{~mm} 2$-mercaptoethanol and $15 \%$ glycerin), and after dialyzed against the same buffer, applied to a hydroxylapatite column $(2.6 \times 12 \mathrm{~cm})$ equilibrated beforehand with buffer II. The column was eluted with a $0.05 \sim 0.25 \mathrm{M}$ potassium phosphate gradient in the presence of 2 mм 2-mercaptoethanol and $15 \%$ glycerin. The flow rate was $0.2 \mathrm{~g} \mathrm{per}$ min and $10-\mathrm{g}$ portion was collected. An aliquot was used for assay of ${ }^{1+} \mathrm{C}$-Phe-tRNA binding or polyphenylalanine synthesis. The results obtained are shown in Fig. 1. ${ }^{14} \mathrm{C}$-Rhe-tRNA binding activity and polyphenylalanine synthesizing activity were eluted at the same position.

Resolution of elongation factors on Sepharose $6 B$. The active fractions (No. 20 40) of Fig. 1 were pooled and precipitated with 0.8 saturation of ammonium sulfate. The precipitate was dissolved in $5 \mathrm{ml}$ of buffer III $(0.05 \mathrm{M}$ Tris- $\mathrm{HCl}$ buffer, $\mathrm{pH} 7.6,0.05 \mathrm{M} \mathrm{KCl}, 10 \%$ glycerin and $2 \mathrm{~mm} 2$-mercaptoethanol) and applied to a Sepharose $6 \mathrm{~B}$ column $(1.6 \because 100 \mathrm{~cm})$ equilibrated beforehand with buffer III. The flow rate was $0.25 \mathrm{~g}$ per min and 4-g portion was collected. An aliquot was used for assay of ${ }^{14} \mathrm{C}$-Phe-tRNA binding and polyphenylalanine synthesis. As shown in Fig. 2 two peaks of binding (EF-1) activity were observed. The former has mol. wt. of about $1.6 \times 10^{6}$ and the latter has mol. wt. of about $6 \times 10^{4}$. They were termed as $\mathrm{EF}-1_{\mathrm{H}}$ and $\mathrm{EF}-1_{\mathrm{L}}$, respectively. $\mathrm{EF}-1_{\mathrm{L}}$ and $\mathrm{EF}-2$ were not separated on this column.

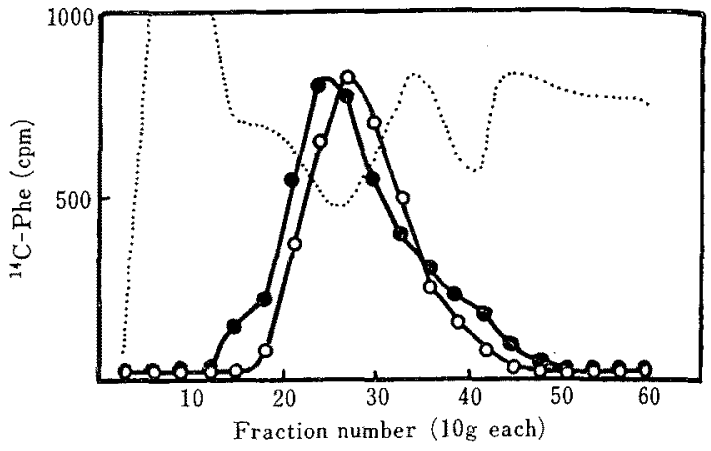

Fig. 1. Chromatography of Crude Elongation Factors on Hydroxylapatite.

The crude elongation factors fractionated with ammonium sulfate was chromatographed on a hydroxylapatite column and assayed for EF-1 (O-O) and EF-2 (-) activities as described under MATERIALS AND METHODS. Elution profile of protein was measured by the method of Lowry (---.--).

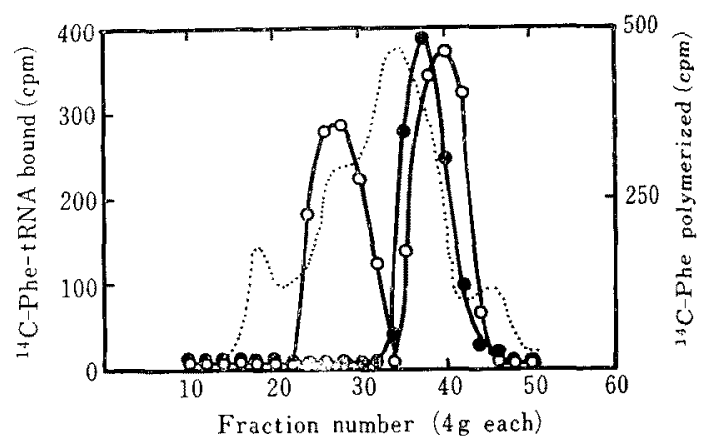

Fig. 2. Gel Filtration of Crude Elongation Factors on Sepharose 6 B.

The active fractions on hydroxylapatite were chromatographed on a Sepharose $6 \mathrm{~B}$ column and assayed for EF-1 (O-O) and EF-2 (-) activities as described under MATERIALS AND METHODS.

Resolution of $E F-I_{L}$ and $E F-2$ on Sephadex G-200. The fractions (No. $35 \sim 46$ ) of Fig. 2 which contain EF-1 ${ }_{L}$ and EF-2 were pooled and concentrated to $5 \mathrm{ml}$ by ultrafiltration (UM-2, Amicon). Five $\mathrm{ml}$ of sample was applied to a Sephadex G-200 column $(2.5 \times 40 \mathrm{~cm})$ equilibrated with buffer III. The flow rate was $0.25 \mathrm{~g}$ per min and $5-\mathrm{g}$ portion was collected. An aliquot was used for assay of ${ }^{14} \mathrm{C}$-Phe-tRNA binding and polyphenylalanine synthesis. As shown in Fig. 3 partial resolution of EF-1 $1_{L}$ and $E F-2$ was achieved. Fractions (No. 23 33) which did not contain EF-2 were pooled and kept at $-25^{\circ} \mathrm{C}$. This EF-1 1 preparation was used for further experiments involving the properties of the factor.

Purification of EF-2 on DEAE-cellulose. The EF-2 fractions (No. $15 \sim 25$ ) of Fig. 3 were pooled and ap- 


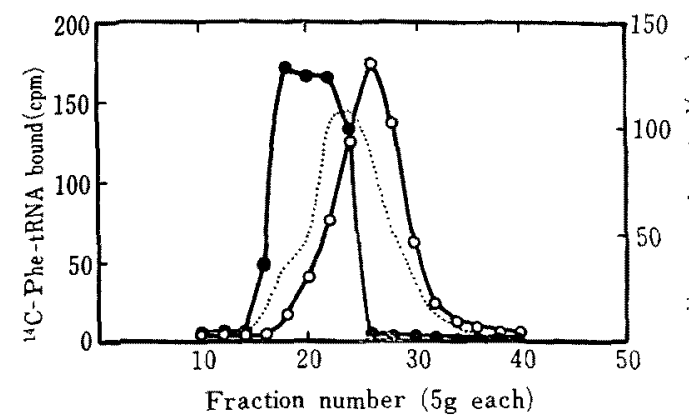

FIG. 3. Resolution of EF-1 $\mathrm{L}$ and $E F-2$ on Sephadex G-200.

The active fractions on Sepharose $6 \mathrm{~B}$ were resolved on a Sephadex G-200 column and assayed for EF-1 $(O-O)$ and $E F-2(-)$ activities as described under Materials AND Methods.

plied to a DEAE-cellulose column equilibrated with buffer III, and eluted with a $0.05 \sim 0.5 \mathrm{M}$ potassium chloride gradient in buffer III. The flow rate was $0.33 \mathrm{~g}$ per min and $5 \mathrm{~g}$ portion was collected. An aliquot was used for assay of ${ }^{14} \mathrm{C}$-Phe-tRNA binding and polyphenylalanine synthesis. As shown in Fig. 4 good separation of EF-2 and EF-1 $1_{L}$ was achieved. EF -2 fractions (No. $12 \sim 18$ ) were pooled and kept at $-25^{\circ} \mathrm{C}$. This EF-2 preparation was used for further experiments involving the properties of the factor.

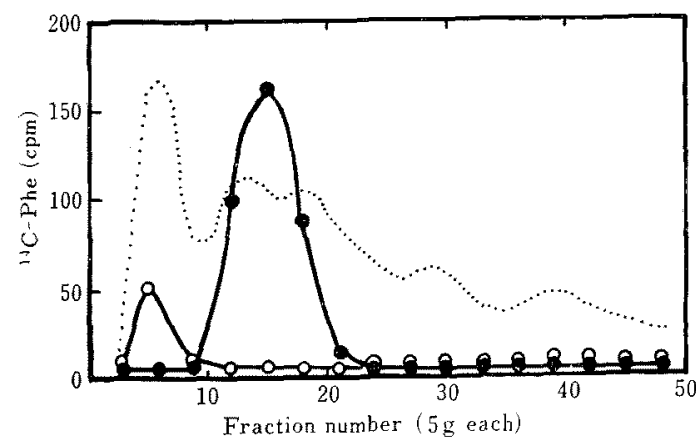

Fig. 4. Chromatography of EF-2 on DEAE-cellulose.

The EF-2 fractions on Sephadex G-200 were chromatographed on a DEAE-cellulose column and assayed for EF-1 (O-O) and EF-2 (-O) activities as described under Materials and MethoDs.

Purification of EF- $\mathrm{l}_{H}$ with 2nd hydroxylapatite chromatography. The EF-1 $1_{\mathrm{H}}$ fractions (No. 22 31) of Fig. 2 were pooled and precipitated with 0.8 saturation of ammonium sulfate. The precipitate was dissolved in $5 \mathrm{ml}$ of buffer II, and after dialyzed against the same buffer, applied to a hydroxylapatite column $(2.6 \times 8 \mathrm{~cm})$. The column was eluted as described before. As shown in Fig. 5 EF-1 activity was eluted at about $0.1 \mathrm{M}$ potassium phosphate. The EF-1 fractions (No. 15 23) were pooled and after dialyzed against buffer 111 kept at $-25^{\circ} \mathrm{C}$. This preparation was used for further experiments involving the properties of the factor.

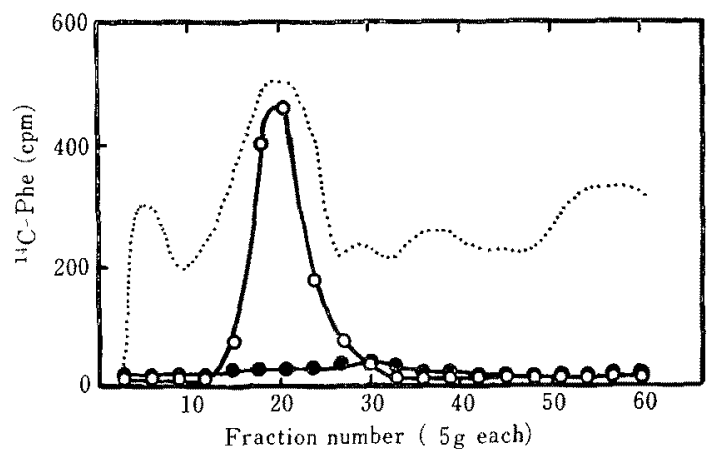

FIG. 5. Chromatography of EF-1 ${ }_{\mathrm{H}}$ on Hydroxylapatite.

The EF-1 1 fractions on Sepharose 6 B were chromatographed on a hydroxylapatite column and assayed for $E F-1 \quad(O-O)$ and $E F-2 \quad(-\bullet)$ activities as described under Materials and Methods.

Preparation of elongation factors from germinated pollen. Pine pollen was germinated at $30^{\circ} \mathrm{C}$ for $18 \mathrm{hr}$ on $3 \%$ agar and elongation factors were prepared by the same methods as described for the preparation of elongation factors from ungerminated pollen. All the experiments except for that of Fig. 14 were performed using elongation factors from ungerminated pollen.

Preparation of ${ }^{14} \mathrm{C}$-Phe-tRNA. ${ }^{11} \mathrm{C}$-Phe-tRNA was prepared as described previously, ${ }^{31)}$ using yeast $t R N A$ and silk gland crude phenylalanyl-tRNA synthetase. The specific activity of ${ }^{14} \mathrm{C}$-Phe-tRNA was $3000 \mathrm{cpm}$ (19 $\mathrm{mmole}$ ) per $10 \mu \mathrm{g}$.

Preparation of silk gland elongation factors. Silk gland elongation factors were prepared as described previously. ${ }^{31)}$ Although, the silk gland EF-1 (termed APase I in the paper ${ }^{31}$ ) had been separated into two complementary factors EF-1a (APase I) and EF-1b (APase II), ${ }^{32}$ we used in these experiments EF-1 which contained EF-la and EF-1b.

Binding assay. EF-1-dependent binding of ${ }^{14} \mathrm{C}$ Phe-tRNA to ribosomes was measured by the cellulose nitrate filter technique according to Nirenberg and Leder $^{33}$ in a system containing the followings in a total volume of $0.25 \mathrm{ml}: 50 \mathrm{~mm}$ Tris- $\mathrm{HCl}$ buffer (pH 7.6), $30 \mathrm{~mm} \mathrm{KCl}, 4 \mathrm{mM} \mathrm{MgCl}, 0.4 \mathrm{~mm} \mathrm{GTP}, 6 \mathrm{~mm}$ dithiothreitol, $1.3 A_{200}$ units of ribosomes, $10 \mathrm{hg}$ of poly (U), $10 \sim 20 \mathrm{~kg}$ of ${ }^{14} \mathrm{C}$-Phe-tRNA and EF-1 frac- 
tions. The reaction mixtures were incubated for 10 min at $25^{\circ} \mathrm{C}$, chilled, and diluted with $5 \mathrm{ml}$ of ice-cold buffer I. The diluted mixture was filtered through a membrane filter (TM-2, $0.45 \mu$, Tōyō) and the filter was washed with three $3-\mathrm{ml}$ portion of cold buffer $\mathrm{I}$. The radioactivity on the filter was estimated in a liquid scintillation spectrometer (Aloka, LSC 651) with toluene scintillator. The counting efficiency for ${ }^{14} \mathrm{C}$ was $67 \%$.

Phenylalanine polymerization assay. The EF-2dependent polyphenylalanine synthesis was measured as the incorporation of ${ }^{14} \mathrm{C}$-phenylalanine into peptides insoluble in hot $5 \%$ trichloroacetic acid in the presence of saturating amounts of EF-1. The reaction mixture was as described for the binding assay except that 20 $\mu \mathrm{g}$ of $\mathrm{EF}-1_{\mathrm{H}}$ and $\mathrm{EF}-2$ fractions were added. Incubation was carried out for $20 \mathrm{~min}$ at $37^{\circ} \mathrm{C}$ and $3 \mathrm{ml}$ of $5 \%$ trichloroacetic acid and $1 \mathrm{mg}$ of egg albumin for a carrier were added. This was heated at $90^{\circ} \mathrm{C}$ for 10 min. The acid insoluble material was collected on a glass filter (GB 60, Töyö), washed three times with $5 \%$ trichloroacetic acid and once with ethanol. The radioactivity on the filter was estimated as described above.

Chemicals. Guanosine triphosphate $\left(\mathrm{GTP}-\mathrm{Na}_{3}\right)$ and polyuridylic acid (poly (U)) were obtained from Boehringer Mann. Uniformly labeled $\mathrm{L}^{14} \mathrm{C}$-phenylalanine (spec. act. $522 \mathrm{Ci} /$ mole) was obtained from Radiochemical Centre, Amersham, England.

\section{RESULTS}

Requirement of each factor for polyphenylalanine synthesis

As described above, protein factors of pine pollen required for the polyphenylalanine synthesis have been resolved into two complementary factors: EF-1 and EF-2. Although two forms of EF-1, EF-1 $1_{\mathrm{H}}$ and $E F-1_{\mathrm{L}}$, were obtained, $E F-1_{\mathrm{H}}$ was used for further experiments when otherwise noted. The dependency of polypeptide elongation on EF-1, EF-2, ribosomes, poly (U), GTP, $\mathrm{MgCl}_{2}, \mathrm{KCl}$ and dithiothreitol is shown in Table I. None of the factors could be omitted from the reaction mixture for the synthesis of polyphenylalanine. Figure 6 shows the mutual dependency of polyphenylalanine synthesis on the two elongation factors of pine pollen in the presence of varying concentrations of the other. It was clearly demonstrated that both factors were indispensable for the reac-
Table I. Requirement of Each Factor for Polyphenylalanine Synthesis

\begin{tabular}{lc}
\hline Reaction system & $\begin{array}{c}{ }^{14} \text { C-Phe polymerized } \\
(\mathrm{cpm})\end{array}$ \\
\hline Complete $^{a}$ ) & 1388 \\
minus EF-1 & 36 \\
minus EF-2 & 42 \\
minus ribosome & 33 \\
minus poly (U) & 34 \\
minus GTP & 45 \\
minus $\mathrm{MgCl}$ & 27 \\
minus $\mathrm{KCl}$ & 24 \\
minus dithiothreitol & 35
\end{tabular}

a) Complete system contained components of the standard polymerization assay.
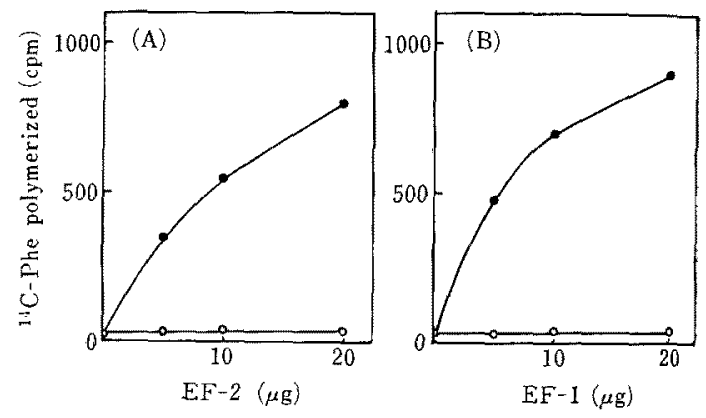

FIG. 6. Mutual Dependency of EF-1 and EF-2 on Polyphenylalanine Synthesis.

(A) The standard incubation conditions were employed with EF-1 saturating and EF-2 varying (-C), or with $\mathrm{EF}-2$ alone $(\mathrm{O}-\mathrm{O})$. (B) The standard incubation conditions were employed with EF-2 saturating and $\mathrm{EF}-1$ varying (-) , or with $\mathrm{EF}-1$ alone $(\mathrm{O}-\mathrm{O})$.

tion.

\section{Effect of inorganic ions on the polyphenylalanine synthesis}

Figure 7 shows an effect of $\mathrm{MgCl}_{2}$ on the polyphenylalanine synthesis. The optimum concentration of $\mathrm{MgCl}_{2}$ was about $4 \mathrm{~mm}$. Figure 8 shows that $\mathrm{KCl}$ stimulated markedly the reaction. The optimum concentration of $\mathrm{KCl}$ was about $30 \mathrm{mM}$. $\mathrm{NH}_{4} \mathrm{Cl}$ gave about the same activity observed for $\mathrm{KCl}$.

\section{Requirement of each factor for the binding of ${ }^{14} \mathrm{C}$-Phe-tRNA to ribosomes}

The dependency of the binding of ${ }^{14} \mathrm{C}$-PhetRNA to ribosomes on EF-1, ribosomes, 


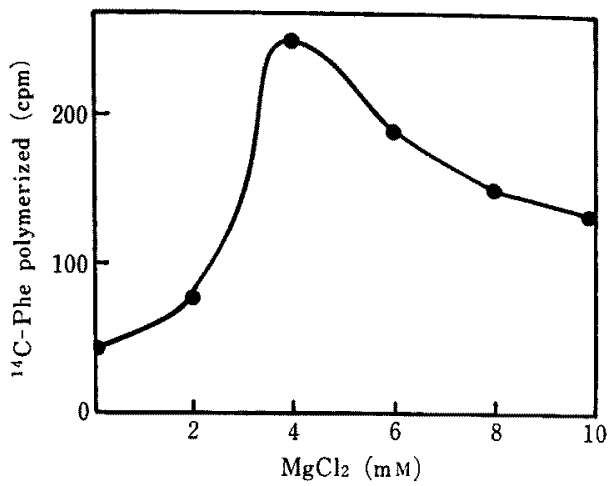

FiG. 7. Effect of $\mathrm{MgCl}_{2}$ Concentration on the Polyphenyl-alanine Synthesis.

The reaction was carried out in the standard incubation conditions except for the use of varying concentrations of $\mathrm{MgCl}_{2}$.

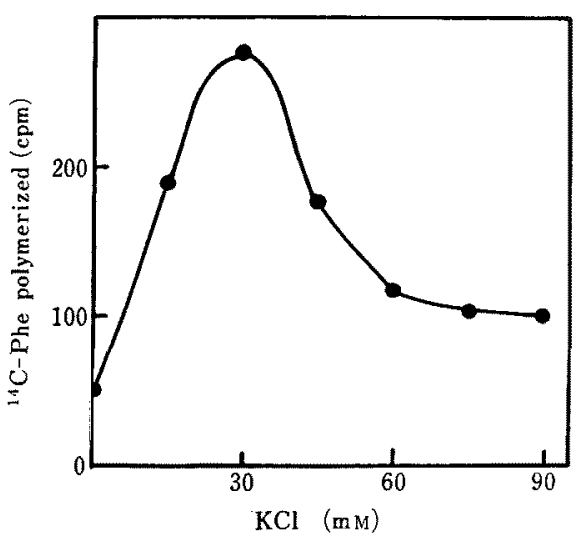

FIG. 8. Effect of $\mathrm{KCl}$ Concentration on the Polyphenylalanine Synthesis.

The reaction was carried out in the standard incubation conditions except for the use of varying concentrations of $\mathrm{KCl}$.

poly (U), GTP, $\mathrm{MgCl}_{2}$ and $\mathrm{KCl}$ is shown in Table II. None of the factors could be omitted from the reaction mixture for the reaction. EF-2 had no activity of the binding reaction.

\section{Effect of inorganic ions on the binding reaction}

Figure 9 shows an effect of $\mathrm{MgCl}_{2}$ on the enzymatic and nonenzymatic binding. Nonenzymatic binding was measured in the absence of EF-1 in the incubation mixtures. Enzymatic binding was calculated as the difference between total binding and nonenzymatic
TABle II. ReQUirement OF EACH FACTOR FOR THE BINDING OF ${ }^{14} \mathrm{C}$-Phe-tRNA to Ribosomes

\begin{tabular}{cc}
\hline Reaction system & $\begin{array}{c}{ }^{14} \mathrm{C}-\mathrm{Phe}-\mathrm{tRNA} \text { bound } \\
(\mathrm{cpm})\end{array}$ \\
\hline Complete $^{a}$ ) & 760 \\
minus EF-1 & 30 \\
minus EF-1 & \\
(plus EF-2) & 35 \\
minus ribosome & 29 \\
minus GTP & 26 \\
minus poly (U) & 32 \\
minus $\mathrm{MgCl}$ & 25 \\
minus $\mathrm{KCl}$ & 33 \\
\hline
\end{tabular}

a) Complete system contained components of the standard binding assay.

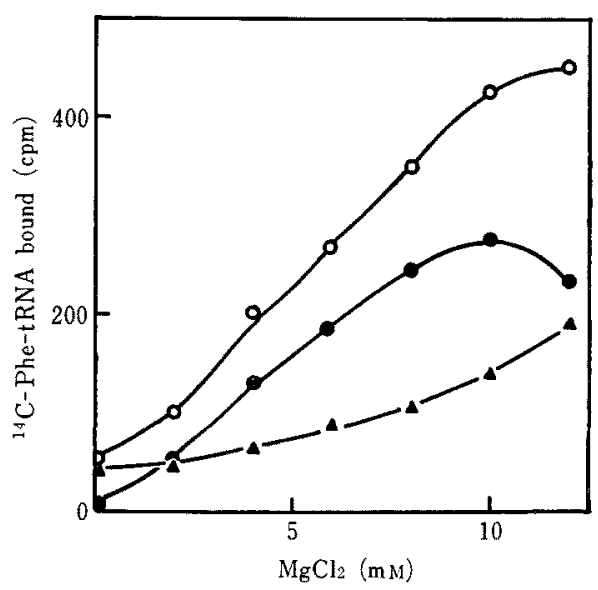

FIG. 9. Effect of $\mathrm{MgCl}_{2}$ Concentration on the Binding of ${ }^{14} \mathrm{C}$-Phe-tRNA to Ribosomes.

The binding was determined in the standard incubation conditions except for the use of varying concentrations of $\mathrm{MgCl}_{2}$ and the results were plotted as the total binding $(\mathrm{O}-\mathrm{O})$. $\mathrm{EF}-1$ was omitted from the reaction mixture to measure the nonenzymatic binding $(\mathbf{\Delta}-\mathbf{\Delta})$. Actual values of enzymatic binding (-) was presented as the difference between the total binding and the nonenzymatic binding.

binding. The values on nonenzymatic binding were proportional to the increased $\mathrm{MgCl}_{2}$ concentrations, whereas the enzymatic binding reached a maximum at about $10 \mathrm{mM} \mathrm{MgCl}_{2}$.

To eliminate the effects of nonenzymatic binding in the standard assays, a concentration of $4 \mathrm{mM} \mathrm{MgCl}_{2}$ was applied. Figure 10 shows an effect of $\mathrm{KCl}$ on the binding reaction. The optimum concentration of $\mathrm{KCl}$ was about $30 \mathrm{~mm}$. $\mathrm{NH}_{4} \mathrm{Cl}$ gave about the 


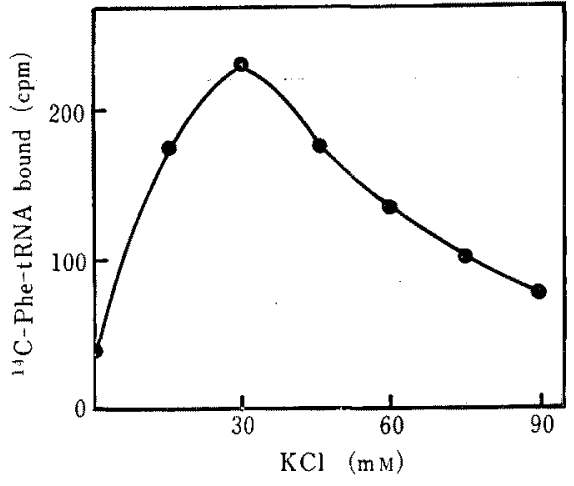

FIG. 10. Effect of $\mathrm{KCl}$ Concentration on the Binding of ${ }^{14} \mathrm{C}$-Phe-tRNA to Ribosomes.

The reaction was carried out in the standard incubation conditions except for the use of varying concentrations of $\mathrm{KCl}$.

same activity observed for $\mathrm{KCl}$.

\section{Effect of GTP concentration on the binding} reaction

Figure 11 shows an effect of GTP concentration on the enzymatic binding of ${ }^{14} \mathrm{C}$-PhetRNA to ribosomes using $\mathrm{EF}-1_{\mathrm{H}}$ (Fig. 11, A)
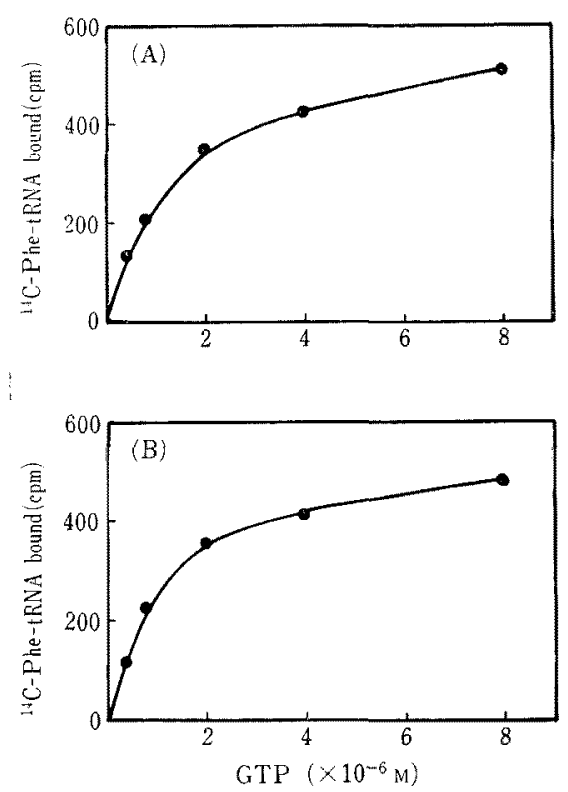

FIG. 11. Effect of GTP on EF-1 $\mathrm{H}^{-}$or EF-1 $\mathrm{L}_{\mathrm{L}}$-dependent Binding of ${ }^{1.4} \mathrm{C}$-Phe-tRNA to Ribosomes.

The enzymatic binding reaction was carried out at various concentrations of GTP in the presence of $\mathrm{EF}-1_{\mathrm{H}}(\mathrm{A})$ or $\mathrm{EF}-1_{\mathrm{L}}$ (B) as described under MATERIALS AND METHODS. or $E F-1_{\mathrm{L}}$ (Fig. 11, B). In both cases the binding activity was completely dependent on the concentration of GTP. From the Lineweaver-Burk plots of these data the $\mathrm{Km}$ values for GTP in the case of $\mathrm{EF}-1_{\mathrm{H}}$ or $\mathrm{EF}-1_{\mathrm{L}}$ were $1.5 \times 10^{-6} \mathrm{M}$ or $1.3 \times 10^{-6} \mathrm{M}$, respectively.

\section{Heat stability of each factor}

Figure 12 shows an effect of heat treatment on the stability of each factor. $E F-1_{\mathrm{H}}$, $E F-1_{\mathrm{L}}$ and $\mathrm{EF}-2$ were incubated at the temperatures indicated for $10 \mathrm{~min}$ and assayed for their residual activities. No significant difference of heat stability was observed among them. However, the heat treatment of $E F-1_{H}$ and $\mathrm{EF}-1_{\mathrm{L}}$ at $40 \sim 45^{\circ} \mathrm{C}$ resulted in about $10 \sim 30 \%$ activation of their binding activities.

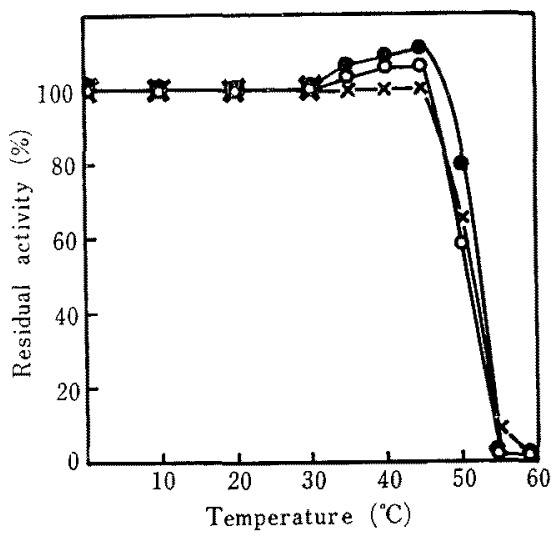

FIG. 12. Effect of Heat Treatment on Each Factor. $E F-1_{\mathrm{H}}(\mathbf{e}), E F-1_{\mathrm{L}}(\mathrm{O})$ or EF-2 (x) in the buffer III was treated for $10 \mathrm{~min}$ at the temperatures indicated and the residual activity of each factor was assayed under the standard reaction condition.

\section{Species specificity of elongation factors}

Species specificity of elongation factors for the polyphenylalanine synthesis was examined using the factors from the silk gland and pollen. As shown in Fig. 13, the combination of the silk gland $E F-1$ and pollen EF-2, or of pollen EF-1 and the silk gland EF-2 was found to be effective for the polyphenylalanine synthesis. There was no detectable activity in the combination of the silk gland EF-1 and pollen $E F-1$, or of the silk gland EF-2 and pollen EF-2 (data were not shown). Similar 

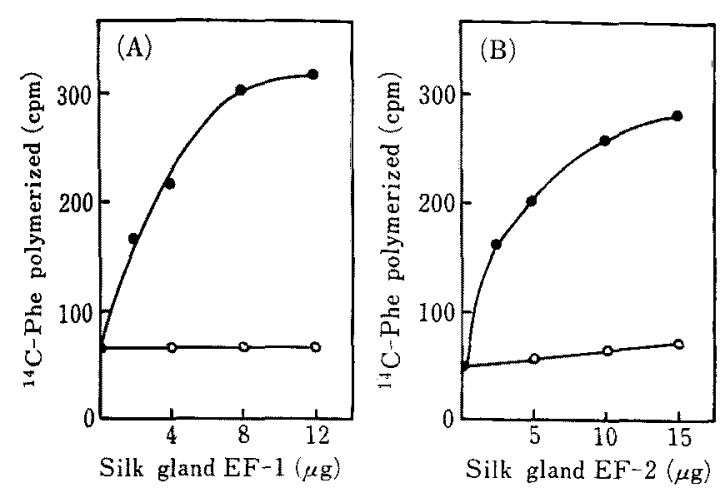

FIG. 13. Cross Complementation between Pine Pollen and Silk Gland Elongation Factors.

(A) The standard incubation condition was employed with pollen EF-2 saturating and with silk gland EF-1 varying $(-)$ ), or with silk gland $E F-1$ alone $(O-O)$ ). (B) The standard incubation condition was employed with pollen EF-1 saturating and with silk gland EF-2 varying (--), or with silk gland EF-2 alone $(\mathrm{O}-\mathrm{O})$.

results were obtained also with silk gland ribosomes and various combinations of the silk gland and pollen elongation factors. No species specificity of elongation factors and ribosomes in the binding reaction was also observed.

\section{Changes of the properties of elongation factors} during germination of pollen

Thus far some properties of elongation factors from ungerminated pollen were described. As EF-1 activity was increased

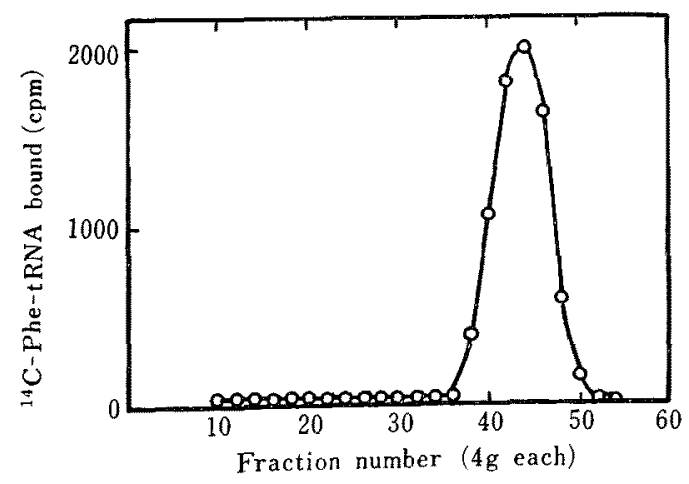

FIG. 14. Gel Filtration of Crude Elongation Factors of Germinated Pollen on Sepharose 6 B.

The details of the operation are given in MATERIALS AND METHODS. Aliquots of $10 \mu 1$ from alternative fractions were assayed for EF-1 activity. during the germination and tube growth (Nunomiya, unpublished data), elongation factors were prepared from germinated pollen as described in the Materials AND METHODS to compare their properties with that of ungerminated pollen. As shown in Fig. 14, dramatic changes of the elution patterns of EF-1 were observed. In this case only one peak of ${ }^{14} \mathrm{C}$ Phe-tRNA binding activity was observed. Its mol. wt. was about $6 \times 10^{4}$.

\section{DISCUSSION}

The experiments described here are aimed at constructing a cell-free protein synthesizing system of pollen for using it in the studies on the mechanisms of polypeptide elongation and its control in plant system. The pollen of Pinus densiflora is a good material for these studies mainly for the following reasons. (a) It can be obtained easily in kilo gram order within two or three days. (b) When the pollen was kept in refrigerator at $-20^{\circ} \mathrm{C}$, no appreciable loss of germinating activity was observed for at least two years. (c) Germination of pollen occures within a short period of time (about $10 \mathrm{hr}$ ) and it is easy to control the process of germination. (d) Many enzymes required for the germination were stored in pollen ${ }^{14 \sim 25)}$ and some of their activities were increased during the germination and tube growth. ${ }^{17 \sim 22)}$ (e) Little or no net synthesis of DNA, ribosome and tRNA was observed during the germination with pollen of various species. . $^{34 \sim 36)}$

As described in the results two elongation factors, EF-1 and EF-2, were obtained for the first time from pollen. As EF-1 forms the ternary complex with GTP and aminoacyltRNA (to be published sooner), and catalyzes the binding of ${ }^{14} \mathrm{C}$-Phe-tRNA to ribosomes in the presence of poly $(\mathrm{U})$, it may correspond to mammalian EF-1. ${ }^{37 \sim 12}$ As EF-2 catalyzes the polyphenylalanine synthesis in the presence of complementary factor, EF-1, it may correspond to mammalian $\mathrm{EF}-2 .^{43 \sim 4(7)}$ These correspondences are further confirmed by the facts that absolute interchangeability of 
elongation factor was observed between pollen and the silk gland factors (Fig. 13). As the silk gland factors were interchangeable with the rat liver ${ }^{31}$ and reticulocyte factors, ${ }^{48}$ ) there may be no species specificity among pollen and mammalian elongation factors in the basic mechanisms of polypeptide elongation. As described in the results basic properties of pollen elongation factors in polyphenylalanine synthesis and aminoacyl-tRNA binding are very similar to those of other eukaryotes. Rather low concentration of $\mathrm{KCl}(30 \mathrm{~mm})$ was required for the both reactions. In other eukaryotes higher concentration of $\mathrm{KCl}$ (80 $100 \mathrm{~mm}$ ) was required.

Recently, three elongation factors, EF-1a, EF-1b and EF-2, corresponding to prokaryotic three elongation factors, EF-Tu, EF-Ts and $E F-G$, were obtained also from eukaryotes with silk gland ${ }^{32}$ and pig liver. ${ }^{49}$ ) The attempt to isolate the third factor, $E F-1 b$, from pine pollen was unsuccessful. But the fact that silk gland EF-1b stimulated the EF-1 activity of pollen (to be published sooner) may suggest the existence of the new factor in pollen.

It is well known that factors EF-1 from many eukaryotes contain several forms heterogeneous in size..$^{13,39 \sim 41,50 \sim 54\}}$ These are called "multiple forms," however, their functions are quite unknown. As shown in Fig. 2, ungerminated pine pollen also contains multiple forms of EF-1. Main components are $E F-1_{\mathrm{H}}$ and $E F-1_{L}$ which have a mol. wt. of $1.6 \times 10^{5}$ and $6 \times 10^{4}$, respectively. Some times small amount of higher mol. wt. form of EF-1 which has a mol. wt. of about $5 \times 10^{5}$ was obtained. Although, various forms of EF-1 were observed in many eukaryotes, it is interesting that main components had mol. wt. of about $1.6 \sim 2.0 \times 10^{5}$ and/or $5 \sim 6 \times 10^{4} .^{10,13,38 \sim 41 \text { ) }}$

To know the functions of multiple forms it is important to research for the changes of the properties of EF-1 corresponding to the changes of physiological conditions. As shown in Fig. 14, in the case of germinated pollen remarkable changes of elution pattern of EF-1 was observed. Only one peak of
EF-1 which has a mol. wt. of about $6 \times 10^{4}$ was observed. It may correspond to $E F-1_{L}$ of ungerminated pollen from its mol. wt. and binding activity. There are at least two explanations for these changes of EF-1. One is that, EF-1 of high mol. wt. is converted to low mol. wt. form in the process of germination. Other explanation is that, the germimated EF-1 became unstable in constructing complexes and dissociated into smaller one in the process of purification. Both explanations may be reasonable at present because high mol. wt. form of EF-1 was still detected when the supernatant fraction of $105,000 \times g$ was analyzed directly on a Sepharose $6 \mathrm{~B}$ column (data were not shown). These data show that EF- $1_{\mathrm{H}}$ of ungerminated and germinated pollen are differed in stability on a hydroxylapatite column. Unpublished data that EF-1 of ungerminated pollen can be purified by a DEAE-cellulose column, while EF-1 of germinated pollen was inactivated on the column also indicate the changes of the properties of EF-1.

These changes of the characteristics of EF-1 in the process of germination may have very important meanings because it is thought that EF-1 acts in the step of aminoacyl-tRNA binding to ribosomes in the form of a low molecular size., ${ }^{9,41,42,50)}$ To clarify the mechanism of the conversion of EF-1 may lead to the understanding of the functions of the multiple forms.

As described above the cell-free protein synthesizing system of pollen may be useful in the further studies for elucidating the controlling mechanisms of protein synthesis in the step of translation.

\section{REFERENCES}

1) P. Lengel and D. Söll, Bacteriol. Rev., 33, 264 (1969).

2) M. Nomura, Bacteriol. Rev., 34, 228 (1970).

3) J. Lucas-Lenard and F. Lipmann, Ann. Rev. Biochem., 40, 409 (1971).

4) "The mechanism of protein synthesis and its regulation," ed. by L. Bosch, North-Holland, Amsterdam, 1972.

5) R. Haselkorn and L. B. Rotham-Denes, Ann. 
Rev. Biochem., 42, 397 (1973).

6) J. E. Allende and M. Bravo, J. Biol. Chem., 241, 5813 (1966).

7) R. J. Mans, Ann. Rev. Pl. Physiol, 18, 127 (1967).

8) "Techniques in protein synthesis," Vol. II, ed. by P. Campbell and J. Sargent, Academic Press Inc., New York, N. Y., 1969, pp. 55 100.

9) A. Tarrago, J. E. Allende, B. Redfield and H. Weissbach, Arch. Biochem, Biophys., 159, 353 (1973).

10) B. Golinska and A. Legocki, Biochim. Biophys. Acta, 324, 156 (1973).

11) T. Twardowski and A. Legocki, ibid., 324, 171 (1973).

12) O. Ciferri and O. Tiboni, Nature New Biol., 245, 209 (1973).

13) R. Bollini, A. N. Soffientini, A. Bertani and G. A. Lanzani, Biochemistry, 13, 5421 (1974).

14) Y. Mäkinen, T. MacDonald, Physiol. Plantarum, 21, 477 (1968).

15) "Pollen development and physiology," ed. by J. Heslop-Harrison, Butterworths, London, 1971, pp. $156 \sim 200$.

16) "Pollen", ed. by R. G. Stanley and H. F. Linskens, Springer-Verlog, Berlin, 1974.

17) T. Katsumata and Y. Togasawa, Nippon Nogeikagaku Kaishi, 42, 1 (1968).

18) T. Katsumata and Y. Togasawa, ibid., 42, 8 (1968).

19) T. Katsumata and Y. Togasawa, ibid., 42, 13 (1968).

20) T. Katsumata, T. Suzuki and Y. Togasawa, Jap. J. Palyn., 16, 29 (1975).

21) D. Southworth and D.B. Dickinson, Plant Physiol, 56, 83 (1975).

22) K. Lendzian and E. Schäfer, Phytochemistry, 12, 1227 (1973).

23) A. Hara, M. Yamamoto, Y. Horita and T. Watanabe, Mem. Fac. Agr., Kagoshima Univ., 8, 27 (1972)

24) J. O. Anderson and J. Nath, Cryobiology, 12, 160 (1975)

25) I. Simeonova and M. Spirova, Fiziol. Rast (Sofia), 1, 69 (1974).

26) H. F. Linskens, Planta, 73, 194 (1967).

27) J. P. Mascarenhas and E. Bell, Biochim Biophys. Acta, 179, 199 (1969).

28) "Pollen development and physiology," ed. by $\mathbf{J}$. Heslop-Harrison, Butterworths, London, 1971, pp. $201 \sim 222$.

29) H. F. Linskens, J. A. M. Schrauwen and R. N. H. Konings, Planta, 90, 153 (1970).

30) A. Tyler, Develop. Biol., Suppl. 1, 170 (1967).
31) S. Ejiri, H. Taira and K. Shimura, I. Biochem., 72, 391 (1972).

32) S. Ejiri, H. Taira and K. Shimura, ibid., 74, 195 (1973).

33) M. Nirenberg and P. Leder, Science, 145, 1399 (1964).

34) C. Kasai, K. Miya, T. Katsumata and Y. Togasawa, J. Fac. Agr. Iwate Univ., 8, 89 (1966).

35) "Pollen development and physiology," ed. by $\mathbf{J}$. Heslop-Harrison, Butterworths, London, 1971, pp. 223 229 .

36) "Pollen development and physiology," ed. by J. Heslop-Harrison, Butterworths, London, 1971, pp. $230 \sim 233$.

37) M. Schneir and K. Moldave, Biochim. Biophys. Acta, 166, 58 (1968).

38) W. L. McKeehan and B. Hardesty, J. Biol. Chem., 244, 4330 (1969).

39) J. F. Collins, H. M. Moon and E. S. Maxwell, Biochemistry., 11, 4187 (1972).

40) K. Iwasaki, S. Nagata, K. Mizumoto and $Y$. Kaziro, J. Biol. Chem., 249, 5008 (1974).

41) H. M. Moon, B. Redfield and H. Weissbach, Proc. Natl. Acad. Sci. U. S., 69, 1249 (1972).

42) A. B. Legocki, B. Redfield, C. K. Liu and H. Weissbach, ibid, 71, 2179 (1974).

43) W. Galasinski and K. Moldave, J. Biol. Chem., 244, 6527 (1969).

44) J. F. Collins, S. Raeburn and E. S. Maxwell, J. Biol. Chem., 246, 1049 (1971).

45) "Methods in Enzymology," Vol. XX, ed. by $\mathbf{K}$. Moldave and L. Grossman, Academic Press Inc., New York, N. Y., 1971, pp. 330 337.

46) D. M. Chuang and H. Weissbach, Arch. Biochem. Biophys., 152, 114 (1972).

47) K. Mizumoto, K. Iwasaki, M. Tanaka and Y. Kaziro, J. Biochem., 75, 1047 (1974).

48) S. Ejiri, H. Taira and K. Shimura, ibid., 72403 (1972).

49) K. Iwasaki, K. Mizumoto, M. Tanaka and Y. Kaziro, ibid., 74, 849 (1973).

50) H. M. Moon, B. Redfield, S. Millard, F. Vane and H. Weissbach, Proc. Natl. Acad. Sci. U. S., 70, 3282 (1973).

51) H. Weissbach, B. Redfield and H. M. Moon, Arch. Biochem. Biophys., 156, 267 (1973).

52) L. E. Manzocchi, A. Tarrago and J. A. Allende, Fed. Eur. Biochem. Soc. Lett., 29, 309 (1973).

53) R. Bolla, H. Weissbach and N. Brot, Arch. Biochem. Biophys., 166, 683 (1975).

54) R. D. Nolan, H. Grasmuk, G. Högenauer and J. Drews, Eur. J. Biochem., 45, 601 (1974). 